\title{
APLICABILIDADE DE KITS DIDÁTICOS DE BAIXO CUSTO PARA O MONITORAMENTO DE QUALIDADE DA ÁGUA EM NASCENTES
}

\author{
Kelvin Dutra Xavier ${ }^{(\mathrm{a}) ;}$ Claudia Werner Flach ${ }^{(\mathrm{b})}$; Débora Pinto Martins ${ }^{(\mathrm{c})}$; Mauricio Meurer ${ }^{(\mathrm{d})}$ \\ (a) Lab. de Estudos Aplicados em Geografia Física/Universidade Federal de Pelotas, kelvin.xavier@hotmail.com \\ ${ }^{\text {(b) }}$ Lab. de Estudos Aplicados em Geografia Física/Universidade Federal de Pelotas, cwflack@ gmail.com \\ (c) Departamento de Geografia e Programa de Pós-graduação em Geografia, Universidade Federal de Pelotas, \\ deby.martins@gmail.com \\ (d) Departamento de Geografia e Programa de Pós-graduação em Geografia, Universidade Federal de Pelotas, \\ mauriciomeurer@yahoo.com.br
}

\section{EIXO: BACIAS HIDROGRÁFICAS E RECURSOS HÍDRICOS: ANÁLISE, PLANEJAMENTO E GESTÃO}

\begin{abstract}
Resumo
O presente trabalho tem como objetivo mostrar a aplicabilidade de kits para monitoramento da qualidade da água em nascentes. Foram utilizados Ecokit, Kit Potabilidade, e o Colipaper, além de medições com Oxímetro, pHmetro e Condutivímetro para medição de parâmetros como nitrito, nitrato, ferro, oxigênio dissolvido, entre outros. Foram escolhidas para realização dos testes três das nascentes da bacia hidrográfica do Arroio do Padre.
\end{abstract}

Palavras chave: Qualidade da àgua, Nascentes, Monitoramento.

\section{Introdução}

A água é o principal recurso natural necessário à manutenção dos processos essenciais de quase todos os seres vivos. Segundo Pinto (2003), a água potável acessível vem se tornando um elemento cada vez mais escasso e de difícil acesso em muitos casos, sendo um dos principais problemas ambientais a serem enfrentados pela populaçao mundial. Assim sendo, a manutenção da qualidade dos corpos d'água em seu máximo possível é de suma importância para o abastecimento e para a utilização da água em suas mais diversas finalidades.

Atividades antrópicas como agricultura, pecuária e retirada da mata ciliar, juntamente com aspectos naturais como a topografia, clima e geologia alteram a água em seus parâmetros químicos, físicos e/ou biológicos. Essas alterações em áreas de nascentes acabam por afetar direta e indiretamente a qualidade da água ao longo de todo o percurso do curso d'água.

Nesse sentido, o monitoramento e a avaliação da qualidade das águas superficiais são fundamentais para a gestão dos recursos hídricos, permitindo a caracterização e a análise de tendências em bacias hidrográficas. Nesse contexto, vem sendo desenvolvido um projeto de “Análise da Qualidade da Água na 


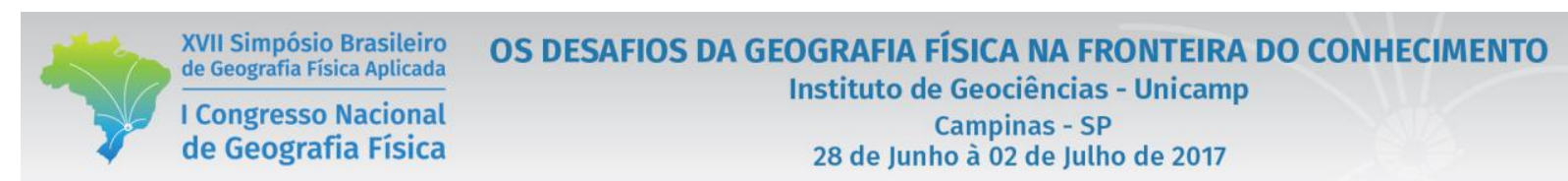

Bacia do Arroio do Padre subsídios para a gestão de recursos hídricos”, que tem por objetivo estabelecer as relações sazonais entre o uso e ocupação da terra e a qualidade ambiental dos recursos hídricos na bacia do Arroio do Padre. Prevê-se a realização de análises da qualidade da água, com bases nos parâmetros físico-químicos, microbiológicos, concentração de nutrientes e de carga de sólidos totais e em suspensão, com o intuito de identificar os principais impactos decorrentes das atividades antrópicas desenvolvidas na área da bacia sobre cursos d'água (MARTINS, 2014).

O presente trabalho tem como objetivo mostrar a aplicabilidade de kits para monitoramento da qualidade da água em nascentes, apresentando os resultados iniciais obtidos para a Bacia do Arroio do Padre.

\section{2. Área de Estudo}

A bacia hidrográfica do Arroio do Padre (Figura 1) possui uma área de $62 \mathrm{Km}^{2}$, e está localizada nos municípios de Arroio do Padre (50\%), Pelotas (40\%) e Turuçu (10\%), entre as coordenadas $31^{\circ} 25^{\prime} 40^{\prime \prime}$ Sul e $52^{\circ} 22^{\prime} 36^{\prime \prime}$ Oeste. Sua maior porção ocorre em Arroio do Padre, município que apresenta uma rede de drenagem composta por arroios, sangas e afluentes (FONSECA, 2014). O uso e ocupação do solo na área da bacia é bastante diversificado, com o predomínio de pequenos agricultores familiares e uma forte vocação agropastoril. Nas áreas de nascentes, predomina a vegetação secundária.

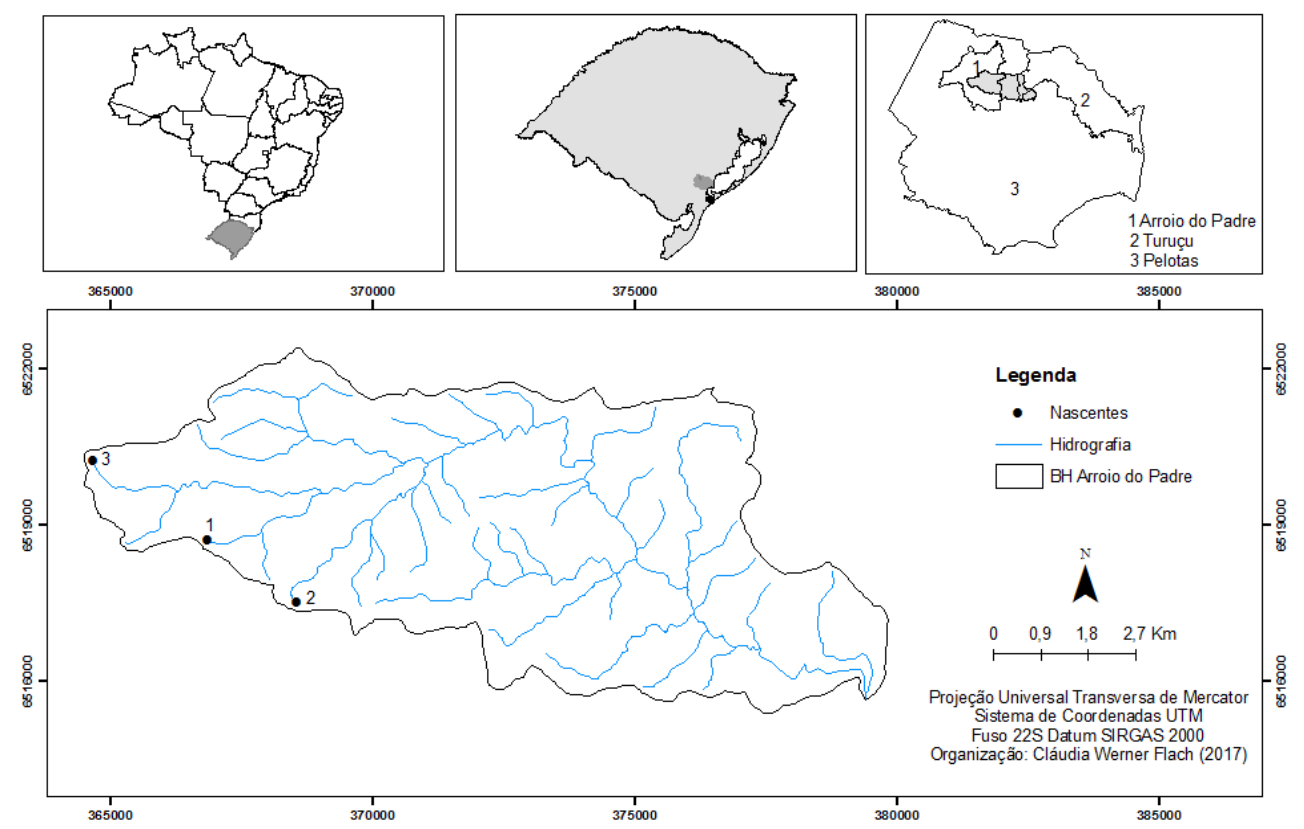

Figura 1.Localização da Bacia Hidrográfica do Arroio do Padre. 


\section{Metodologia e equipamentos}

Foram selecionadas três nascentes na alta bacia do Arroio do Padre para o monitoramento da qualidade da água através dos kits e equipamentos de baixo custo. Esses kits permitem avaliar os seguintes parâmertos: Alcalinidade, Amônia, Cloreto, Dureza, Ferro, Oxigênio Consumido, Ortofosfato, Nitrato e Nitrito, além de $\mathrm{Ph}$, Condutividade elétrica, TDS e Oxigênio dissolvido através dos equipamentos pHmetro, Condutivímetro e Oxímetro respectivamente. Para a obtenção dos resultados, são utilizados reajentes disponibilizados juntamente com os kits. Para os parâmetros Ferro, Ortofosfato e Oxigênio consumido é necessário um período de espera de aproxidamente 10 minutos, já para os parâmetros Nitrato e Nitrito, a espera é de aproximadamente 15 minutos após o uso dos reajentes para a obtenção dos resultados. Para a medição da presença de coliformes é necessária a coleta da amostra d'água através do Colipaper para o armazenamento do mesmo em uma estufa (fornecida juntamente ao kit) por um período de 15 horas, passado esse perído é possivel verificar a presença de colifornes.

\section{Resultados e discussões}

Os resultados obtidos à campo podem ser verificados na Tabela I.

Tabela I- Resultados dos testes

\begin{tabular}{|c|c|c|c|}
\hline Parâmetro & Nascente 1 & Nascente 2 & Nascente 3 \\
\hline Alcalinidade & $20 \mathrm{mg} \mathrm{L}^{-1}$ & $20 \mathrm{mg} \mathrm{L}^{-1}$ & $40 \mathrm{mg} \mathrm{L} \mathrm{-1}$ \\
\hline Amônia & $0.10 \mathrm{mg} \mathrm{L}^{-1}$ & $0.10 \mathrm{mg} \mathrm{L}^{1}$ & $1.0 \mathrm{mg} \mathrm{L}^{-1}$ \\
\hline Cloreto & $20 \mathrm{mg} \mathrm{L}^{-1}$ & $30 \mathrm{mg} \mathrm{L}^{-1}$ & 50 mg L-1 \\
\hline Dureza & 30 mg L-1 & $20 \mathrm{mg} \mathrm{L}^{-1}$ & 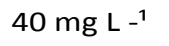 \\
\hline Ferro & $0.25 \mathrm{mg} \mathrm{L}^{-1}$ & $0.25 \mathrm{mg} \mathrm{L}^{-1}$ & $0.50 \mathrm{mg} \mathrm{L}^{-1}$ \\
\hline $\mathrm{O}^{2}$ consumido & $3.0 \mathrm{mg} \mathrm{L}^{-1}$ & $2.0 \mathrm{mg} \mathrm{L-1}$ & - \\
\hline Ortofosfato & 0.0 mg L-1 & $0.0 \mathrm{mg} \mathrm{L-1}$ & $0.75 \mathrm{mg} \mathrm{L}^{-1}$ \\
\hline Nitrato & $2.5 \mathrm{mg} \mathrm{L}-^{-1}$ & $1.0 \mathrm{mg} \mathrm{L}-1$ & $0.1 \mathrm{mg} \mathrm{L}^{-1}$ \\
\hline Nitrito & $0.01 \mathrm{mg} \mathrm{L-1}$ & $0.01 \mathrm{mg} \mathrm{L}^{-1}$ & $0.01 \mathrm{mg} \mathrm{L-1}$ \\
\hline $\mathrm{Ph}$ & 6.35 & 5.95 & 6.19 \\
\hline Temperatura & $17.7^{\circ} \mathrm{C}$ & $18.5^{\circ} \mathrm{C}$ & $17.9^{\circ} \mathrm{C}$ \\
\hline Condut. Elétrica & $160.2 \mu \mathrm{s}$ & $89.7 \mu \mathrm{s}$ & $146 \mu \mathrm{s}$ \\
\hline Tds & $80.2 \mathrm{ppm}$ & $44.8 \mathrm{ppm}$ & - \\
\hline $\mathrm{O}^{2}$ dissolvido & $20 \mathrm{mg} / \mathrm{l}$ & $5,5 \mathrm{mg} / \mathrm{l}$ & $20 \mathrm{mg} / \mathrm{l}$ \\
\hline Coliformes & presentes & presentes & presentes \\
\hline
\end{tabular}

O monitoramento das nascentes mostrou que, das três nascentes monitoradas, a Nascente 2 apresentou valores reduzidos de Oxigênio Dissolvido, enquanto que a Nascente 3, localizada muito próxima da área urbana do município, apresentou elevado valor de Ferro, valor elevado de Cloreto e presença de Ortofosfato. 
Após a realização das avaliações à campo, foi possívela avaliar a aplicabilidade dos kits didáticos. Dentre as vantagens dos kits utilizados, pode-se destacar: custo relativamente baixo para a quantidade de parâmetros e medições capazes de realizar; fácil utilização mesmo por pessoas que não possuem maiores conhecimentos em técnicas de análises laboratoriais; interface simples e de fácil aprendizado; além do tempo para obtenção dos resultados (aproximadamente 50 minutos). Já a principal desvantagem diz respeito à baixa precisão, pois os valores são dados em intervalos e não em valores absolutos, o que pode causar confusão e dificuldade de leitura de alguns parâmetros. No caso do kit de medição de coliformes, os resultados permitiram apenas certificar a presença de coliformes fecais em todas as nascentes, mas não permitiram quantificar a concentração de coliformes.

\section{Conclusões}

Com os resultados obtidos concluímos que os kits adquiridos podem ser utilizados para um estudo inicial e exploratório, possibilitando o conhecimento de áreas mais ou menos impactas através da observação da variação dos parâmetros medidos, permitindo assim que estudos posteriores sejam realizados de maneira mais direcionada e precisa naquelas nascentes que apresentem alterações significativas.

\section{Referências}

ANA - Agência Nacional de Águas. Portal da Qualidade das Águas - Programa Nacional de Qualidade da Água. http://pnqa.ana.gov.br/default.aspx. Acesso em: 10 fev. 2017.

FONSECA, L.C. Impactos Ambientais decorrentes da ação antrópica nas áreas de nascentes da bacia do Arroio do Padre, Arroio do Padre-RS. Trabalho de Conclusão de Curso. Universidade Federal de Pelotas. Pelotas/RS. 2014. 67p..

MARTINS, D.P. Análise da Qualidade da Água na Bacia do Arroio do Padre: subsídios para a gestão de recursos hídricos. Universidade Federal de Pelotas, 2014. 